\title{
Mechanical Analysis of the DSB Cross-Section*
}

\author{
Y. Chen \\ Superconducting Super Collider Laboratory ${ }^{\dagger}$ \\ 2550 Beckleymeade Ave. \\ Dallas, TX 75237
}

May 1993

*Presented at the Fifth Annual International Symposium on the Super Collider, May 6-8, 1993 San Francisco, CA.

† Operated by the Universities Research Association, Inc., for the U.S. Department of Energy under Contract No. DE-AC35-89ER40486.

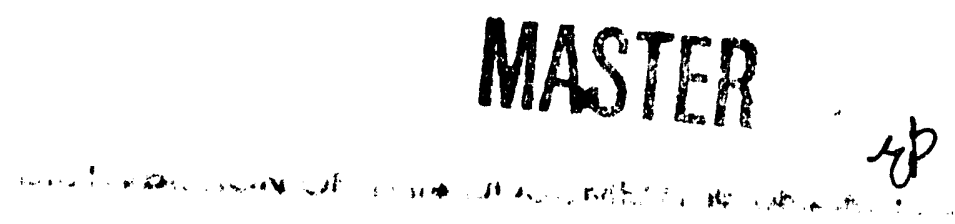




\title{
MECHANICAL ANALYSIS OF THE DSB CROSS-SECTION
}

\author{
Yanping Chen \\ Superconducting Super Collider Laboratory* \\ 2550 Beckleymeade Ave. \\ Dallas, TX 75237-3997
}

\section{INTRODUCTION}

This paper presents the preliminary mechanical finite element analysis for the SSCL designed DSB dipole magnet. This SSCL version $50 \mathrm{~mm}$ aperture dipole magnet is for the SSCL High Energy Booster with nineteen turns, three wedges for inner coil and twenty six turns, one wedge for outer coil, the round collar is nineteen mm thick, the yoke and the shell are adopted from the design for quadrupole QSE101.

The main purposes of this mechanical study are to ensure that there are no excessive stresses in the cold mass under different loading, to avoid coils unloading from the collar at excitation of $6500 \mathrm{~A}$, to ensure collar-to-yoke, line-to-line fit after welding the shell, and also to ensure the yoke midplane gaps are closed at an operating current of $6500 \mathrm{~A}$.

Therefore, the analyses performed include magnet assembly (collaring) to $69 \mathrm{Mpa}$ azimuthal stress at the inner coil pole and $55 \mathrm{Mpa}$ azimuthal stress at the outer coil pole; shell welding to $207 \mathrm{Mpa}$ azimuthal stress in the shell; magnet cooldown to $4.25 \mathrm{~K}$; and Lorentz excitation at a current of $6500 \mathrm{~A}$.

\section{FINITE ELEMENT MODEL}

Analysis is performed on a quarter model since the geometry and loading are symmetrical.

\section{Model Assumption 1}

* The model assumes plane stress analysis

* All materials are linearly elastic, except that plasticity is considered for the collar. The coils are orthotropic in radial and azimuthal directions both for Young's Moduli and thermal coefficient. The Young's Moduli for the inner coil are higher than that for the outer coil due to the stiffness increment caused by curing the inner coil twice.

\footnotetext{
* Operated by the Universities Research Association, Inc., for the U. S. Department of Energy under Contract No. DE-AC35-89ER40486.
} 
* Young's Modulus for each material at $4.25 \mathrm{~K}$ is higher than that at room temperature

* All contact surfaces are assumed frictionless or bound

* No interferences exist between coil turns and wedges

* The front collar is spot welded with the back collar, so that the displacements of front and back collars in the horizontal midplane are the same radially, but the same magnitude in the opposite direction azimuthally, also similarly in the vertical plane

* Lorentz forces are calculated with infinite permeability iron.

* Half collaring prestress is modeled by specifying coil midplane displacement, another half by specifying an interference between coils and collar at pole planes.

\section{Material Properties ${ }^{1}$}

\section{Inner Layer Insulated Cable}

Outer Layer Insulated Cable

Copper wedge, Brass Shoe, Brass Key

Kapton

Intercoil Spacer

Nitronic 40

Stainless Steel

Iron Yoke

Stainless Steel Shell

\section{Elastic Modulus}

$$
\begin{gathered}
\text { Room Temperature } \\
\text { Eazim }=11,000 \mathrm{Mpa} \\
\text { Eradial }=17,600 \mathrm{Mpa} \\
\text { Cold Temperature } \\
\text { Eazim }=13,200 \mathrm{Mpa} \\
\text { Eradial }=18,320 \mathrm{Mpa}
\end{gathered}
$$

Roorn Temperature

Eazim $=10,000 \mathrm{Mpa}$

Eradial $=16,000 \mathrm{Mpa}$

Cold Temperature

Eazim $=12,300 \mathrm{Mpa}$

Eradial $=17,120 \mathrm{Mpa}$

Room Temperature

$E=120,000 \mathrm{Mpa}$

Cold Temperature $E=150,000 \mathrm{Mpa}$

Room Temperature

$\mathrm{E}=3,000 \mathrm{Mpa}$

Cold Temperature $\mathrm{E}=3,810 \mathrm{Mpa}$

Room Temperature $E=10,000 \mathrm{Mpa}$

Cold Temperature $\mathrm{E}=12,300 \mathrm{Mpa}$

Room Temperature $\mathrm{E}=195,000 \mathrm{Mpa}$ Eplastic $=40,000 \mathrm{Mpa}$ yield stress $=620 \mathrm{Mpa}$

Cold Temperature $E=206,700 \mathrm{Mpa}$

Room Temperature $\mathrm{E}=205,000 \mathrm{Mpa}$

Cold Temperature $E=211,000 \mathrm{Mpa}$

Room Temperature $E=195,000 \mathrm{Mpa}$

Cold Temperature $\mathrm{E}=206,700 \mathrm{Mpa}$

\section{Thermal Coefficient}

aazim $=1.40 \mathrm{e}-5(1 / \mathrm{K})$

aradial $=1.53 \mathrm{e}-5(1 / \mathrm{K})$

aazim $=1.40 \mathrm{e}-5(1 / \mathrm{K})$

aradial $=1.53 \mathrm{e}-5(1 / \mathrm{K})$

$\alpha=1.11 \mathrm{e}-5(1 / \mathrm{K})$

$\alpha=2.00 \mathrm{e}-5(1 / \mathrm{K})$

$\alpha=1.8 \mathrm{e}-5(1 / \mathrm{K})$

$\alpha=0.92 \mathrm{e}-5(1 / \mathrm{K})$

$\alpha=0.698 \mathrm{e}-5(1 / \mathrm{K})$

$\alpha=1.073 \mathrm{e}-5(1 / \mathrm{K})$ 


\section{RESULT}

Table 1. Inner and outer coil average azimuthal stresses; collar horizontal and vertical deflections at pole under various loading

\begin{tabular}{|c|c|c|c|c|}
\hline \multirow[t]{2}{*}{ Loading Condition } & \multirow{2}{*}{$\begin{array}{l}\text { Pole Stres } \\
\text { Inner }\end{array}$} & \multirow{2}{*}{$\begin{array}{l}\text { (Mpa) } \\
\text { Outer }\end{array}$} & \multicolumn{2}{|c|}{ Collar Deflection (mm) } \\
\hline & & & Horizontal & Vertical \\
\hline Collaring & 69.7 & 54.8 & 0.0264 & 0.0995 \\
\hline Welding to $207 \mathrm{Mpa}^{*}$ & 85.9 & 68.0 & 0.00655 & 0.0586 \\
\hline Cooldown to $4.25 \mathrm{~K}^{*}$ & 56.5 & 51.2 & 0.0324 & 0.0459 \\
\hline Energization to $1000 \mathrm{~A}^{*}$ & 55.7 & 50.6 & 0.0331 & 0.0454 \\
\hline Energization to $2000 \mathrm{~A}^{*}$ & 53.3 & 49.0 & 0.0353 & 0.0441 \\
\hline Energization to $3000 \mathrm{~A}^{*}$ & 49.3 & 46.2 & 0.0388 & 0.0418 \\
\hline Energization to $4000 \mathrm{~A}^{*}$ & 43.7 & 42.3 & 0.0431 & 0.0387 \\
\hline Energization to $5000 \mathrm{~A}^{*}$ & 36.7 & 37.4 & 0.0486 & 0.0347 \\
\hline Energization to $6000 \mathrm{~A}^{*}$ & 28.0 & 31.4 & 0.0554 & 0.0297 \\
\hline Energization to $6500 \mathrm{~A}^{*}$ & 23.1 & 28.0 & 0.0593 & 0.0268 \\
\hline
\end{tabular}

Table 2. Collar to yoke contact force; midplane yoke to yoke contact force and minimum and maximum gap under various loading

Loading Condition

Welding to $207 \mathrm{Mpa}$

Cooldown to $4.25 \mathrm{~K}$

Energization to $1000 \mathrm{~A}$

Energization to $2000 \mathrm{~A}$

Energization to $3000 \mathrm{~A}$

Energization to $4000 \mathrm{~A}$

Energization to $5000 \mathrm{~A}$

Energization to $6000 \mathrm{~A}$

Energization to $6500 \mathrm{~A}$
Collar-Yoke Contact F (N)
Horizontal Vertical

942

165

172

198

244

312

400

511

578
1012

332

327

315

297

274

246

213

198
Yoke-Yoke

(N)

0

1590

1594

1607

1625

1649

1678

1712

1728
Fax. Min. Gap

$(\mathrm{mm})$

$$
0.04880 .0353
$$

$0 \quad 0$

$0 \quad 0$

$0 \quad 0$

$0 \quad 0$

$0 \quad 0$

$0 \quad 0$

$0 \quad 0$

$0 \quad 0$

Where deflection "*" is calculated as:

Deflection $=$ R. $\alpha . \mathrm{dT}-$ Abs. Dfl.

$\mathrm{d} \mathrm{T}=293-4.25 \mathrm{~K}$

$\mathrm{R}=$ collar outer most radius at horizontal and vertical directions

$\alpha=$ thermal coefficient

Abs. Dfl. = absolute deflection of the point from ANSYS analysis

Here, R. $\alpha . \mathrm{dT}$ are $0.1998 \mathrm{~mm}$ and $0.1838 \mathrm{~mm}$ in vertical and horizontal directions.

In this analysis, the stretching stress in the collar near the key way is about $720 \mathrm{Mpa}$.

For the comparison of this round collar design with an anti-oval collar design, the analysis for the anti-oval collar with $0.1 \mathrm{~mm}$ total ovality is performed also. The results show that there is no contact between collar and yoke, which means that collar is free to move inside the yoke, but they are in contact at operating current. Some experts insist on collar to yoke contacting all the time after cooldown in order to reduce the risk of quench due to the movement of the collar inside the yoke, others consider that no contact between the collar and the yoke after cooldown and at low excitation currents is acceptable as long as they contact each other at operating current. 


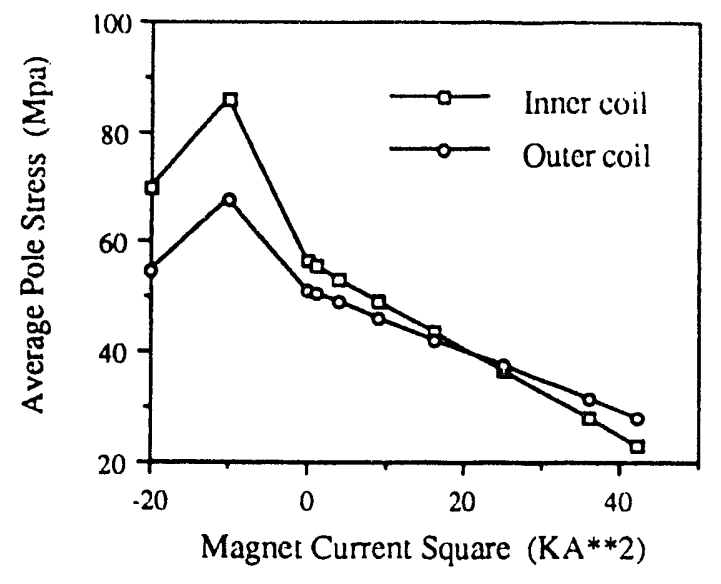

Figure 1. Calculated average azimuthal pole stress pole stress for round collar

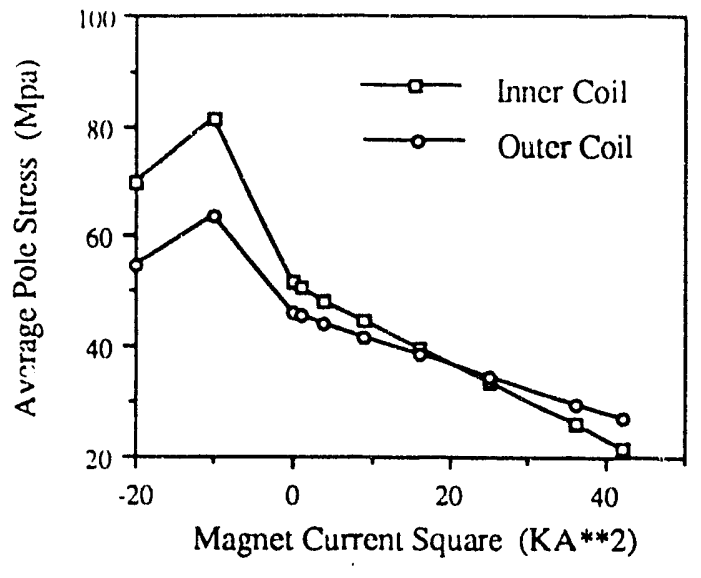

Figure 2. Calculated average azimuthal for anti-oval collar

From the data in Table 1, the calculated average azimuthal pole stress for a coil under different loading is shown in Figure 1. The same type of curve for the anti-oval collar is plotted in Figure 2. As can be seen in the figures, the pole stress for the round collar is only several Mpa greater than the corresponding one for the anti-oval collar.

\section{CONCLUSION}

From the ANSYS model analysis, it is clear that coil prestresses are far away from unloading at operating current; that yoke and collar are in tight contact after welding and remain in good contact after cooldown and excitation to $6500 \mathrm{~A}$; also that the yoke midplanes contact after cooldown and thereafter, although there is no any contact between them after welding.

However the analysis also shows that the tensile stress in the collar near the key way is over yielding stress after collaring, but this would not effect the overall mechanical performance of the magnet, since it is in a highly localized area.

According to this analysis, DSB with round collar would perform similarly to the collider dipole in mechanical aspects.

\section{ACKNOWLEDGMENTS}

My thanks to Nick Hassan and J. Turner for their support

\section{REFERENCES}

1. J. Turner, G. Spigo, Y. Chen: Mechanical Analysis of the QSE101 Cross-Section, March, 1992 

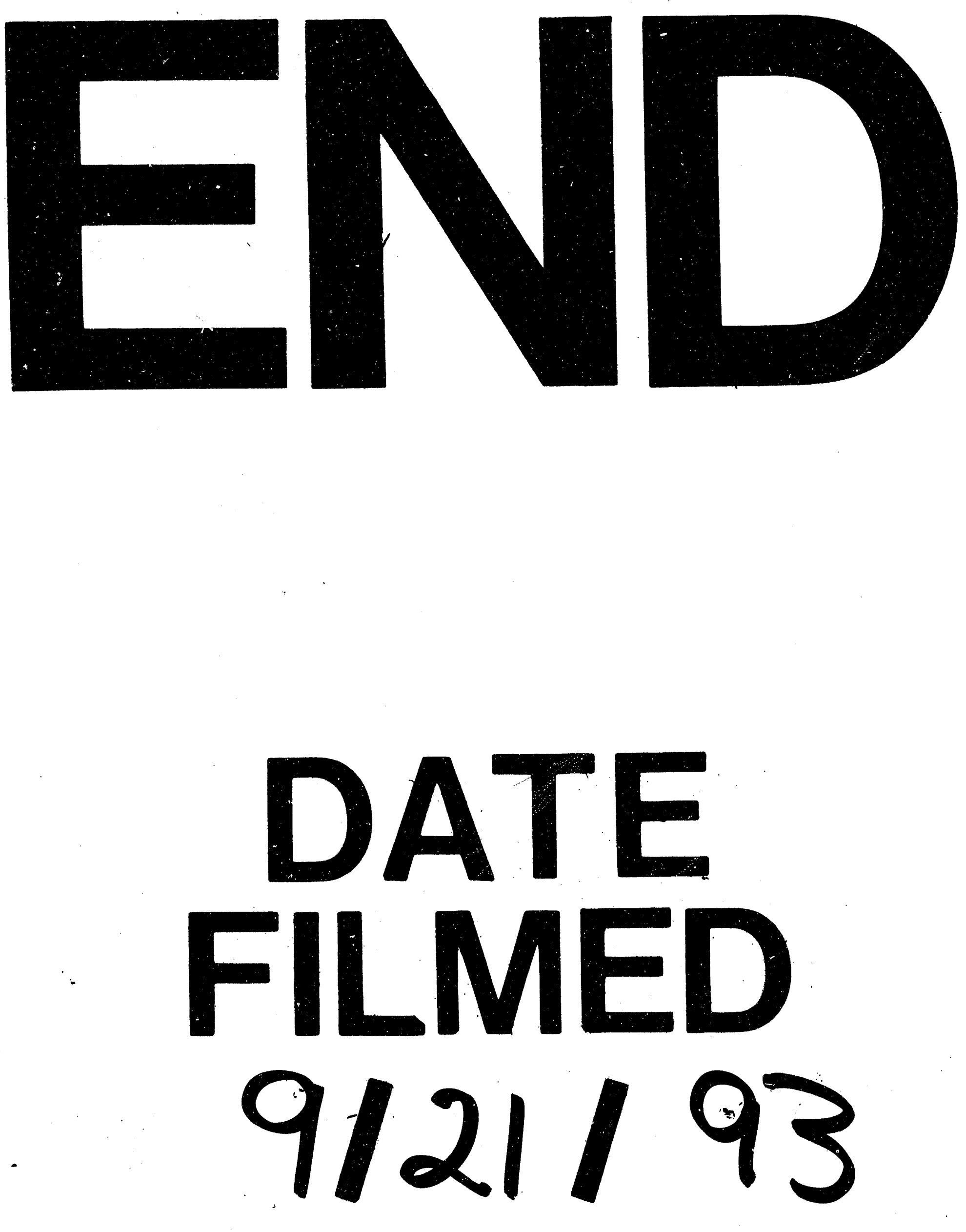
